\section{Modelo teórico/ didático do gênero artigo de opinião: ferramentas para análise do gênero}

Theoretical/didactic model of the opinion piece genre: tools
Rithielle Aparecida CASTELLANI (UENP) rithielle1995@hotmail.com

Eliana Merlin Deganutti de BARROS (UENP) edeganutti@hotmail.com

Recebido em: 01 de fev. de 2018. Aceito em: 21 de jun. de 2018.

\title{
00000000000
}

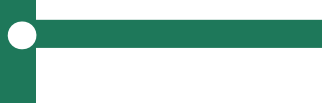

CASTELLANI, Rithielle Aparecida;

BARROS, Eliana Merlin Deganutti de.

Modelo teórico/didático do gênero

artigo de opinião: ferramentas para

análise do gênero. Entrepalavras,

Fortaleza, v. 8, n. 2, p. 196-214, maio/

ago. 2018.
Resumo: Este artigo é resultado de pesquisas realizadas no projeto "Gêneros da mídia jornalística como objeto de transposição didática externa", o qual está inserido no grupo de pesquisa DIALE (CNPq/UENP). Em sua fundamentação teórica, o projeto pauta-se nos estudos dos Interacionismo Sociodiscursivo (BRONCKART, 2003), especialmente os voltados para a transposição didática de gêneros textuais. A pesquisa teve como principal objetivo analisar o processo de modelização do gênero artigo de opinião a partir da produção de um modelo teórico/ didático e de uma Sequência Didática de gênero (DOLZ; NOVERRAZ; SCHNEUWLY, 2004). Para este artigo, o foco é apresentar o modelo teórico e o modelo didático do gênero, os quais serviram de base no momento da produção da SDG.

Palavras-chave: Modelo teórico. Modelo didático. Artigo de opinião. 
Abstract: This paper is the result of researches done in the project "Genres of the journalistic media with the external didactic transposition objective", which is inserted in the research group DIALE (CNPq/UENP). In its theoretical base the project is based on the Interactionism Sociodiscursive studies (ISD), especially the ones facing the didactic transposition of textual genres. The research had as its main objective analyze the process of modeling the genre opinion article from the production of a theoretical didactic model and from a genre didactic sequence (SDG). For this article, the focus is to present the theoretical model and the genre didactic model, which served as base at the moment of the SDG production.

Keywords: Theoretical model. Didactic Model. Opinion article.

\section{Introdução}

Os diferentes documentos oficiais da educação (BRASIL, 1998; PARANÁ, 2008; BRASIL, 2006) que servem de parâmetro para o ensino de Língua Portuguesa propõem que os professores tomem como seus objetos de ensino as diferentes práticas de linguagem, essas sempre configuradas em gêneros textuais presentes na sociedade. Entretanto, ainda há certa carência e dúvidas por parte de muitos educadores no momento de trabalhar didaticamente nessa perspectiva. Acreditamos que isso aconteça, pois muitos ainda não dispõem de ferramentas metodológicas para guiar o ensino voltado para essas práticas.

Pensando nessa necessidade, desenvolvemos este artigo, que traz resultados de pesquisas desenvolvidas no projeto "Gêneros do jornal como objetos de transposição didática" (vinculado ao Grupo de Pesquisa DIALE, CNPq), o qual toma como objeto as ações do subprojeto PIBID Programa Institucional de Bolsa de Iniciação à Docência (PIBID-CAPES) - "Letramentos na escola: práticas de leitura e produção textual" (eixo: Gêneros do jornal), as quais baseiam-se em um trabalho colaborativo fundamentado na metodologia das sequências didáticas de gêneros (SDG).

Dessa forma, há a articulação entre dois projetos: o projeto de pesquisa e o subprojeto PIBID; ambos desenvolvidos na Universidade Estadual do Norte do Paraná - Campus Cornélio Procópio - (UENP) e orientados teoricamente pelos estudos do Interacionismo Sociodiscursivo (ISD - BRONCKART, 2003), principalmente nas pesquisas voltadas para a transposição didática (CHEVALLARD, 1984, 1989) dos gêneros textuais.

Tais projetos centram-se no trabalho com os gêneros jornalísticos, visto que essa esfera recebe muita atenção em sala de aula e sua abordagem é sugerida pelos documentos oficiais da educação (BRASIL, 1998; PARANÁ, 2006; BRASIL, 2008). Entretanto, como ressalta Bonini (2003, p. 205), "ainda são pouco conhecidos, em termos acadêmicos, os mecanismos linguísticos/sociais que caracterizam estes gêneros textuais", ou seja, ainda há dificuldades no momento de didatizar esses gêneros. 
v. 8 (2)

$196-214$

mai/ago 2018

Pensando nessa dificuldade do professor em transpor o gênero jornalístico para um contexto de ensino determinado, apresentamos nesse artigo duas etapas que permitem ao educador visualizar as potencialidades desse objeto comunicativo - gênero - como um objeto de ensino.

\section{Caminhos da pesquisa}

O gênero textual, antes de ser levado para a sala de aula precisa sofrer "transformações" a fim de que se torne, realmente, um objeto de ensino, pensando nisso, apresentamos nesse trabalho dois processos de modelização do gênero artigo de opinião (objeto de ensino da SDG desenvolvida durante PIBID de 2014).

No primeiro momento, trazemos a modelização teórica do gênero (BARROS, 2012a), a partir da qual são reveladas as capacidades de linguagem que abrangem a produção e apropriação desse objeto da língua. Na modelização teórica, não há uma preocupação imediata com o ensino desse gênero, ou seja, é um levantamento prévio que, posteriormente, será transposto e pensado para um contexto de ensino determinado a partir de um modelo didático.

Em seguida, trazemos o modelo didático (DE PIETRO; SCHNEUWLY, 2003) desse mesmo gênero, o qual foi pensado e produzido a partir do levantamento teórico inicial. No entanto, a produção do modelo didático é feita visando um contexto especifico, com objetivos delineados, ou seja, visando o ensino/aprendizagem desse gênero.

Para tanto, nosso objetivo com esse trabalho é ampliar as possibilidades do ensino de gêneros jornalísticos, em especial o artigo de opinião, através da metodologia da SDG, focando especialmente no processo de modelização do gênero, de um objeto comunicativo da língua a um objeto com potencialidades ensináveis.

Estruturalmente, o artigo é dividido nos seguintes tópicos: a) "O contexto de geração dos dados de pesquisa", o qual apresenta a descrição do locus de pesquisa, a fim de contextualizar os resultados da pesquisa apresentados; b) "A transposição didática pelo viés do Interacionismo Sociodiscursivo", tópico que traz um breve panorama de como a vertente didática do ISD aborda metodologicamente a transposição didática de gêneros para o contexto de ensino da língua; c) como complemento do tópico anterior, "A modelização do objeto de ensino: o primeiro processo da transposição didática" aborda teoricamente o objeto deste artigo - o processo de modelização dos 
objetos de ensino pelo viés do ISD; d) a parte analítica deste artigo destina-se a trazer "O processo de modelização do gênero 'artigo de opinião'", tendo como respaldo ações desenvolvidas para o subprojeto PIBID durante a transposição didática externa do referido gênero.

\section{0 contexto de geração dos dados de pesquisa}

Durante o desenvolvimento da primeira etapa da nossa pesquisa, o objeto de estudo foi o jornal Folha de Londrina, a partir do qual elaboramos um modelo teórico (BARROS, 2012a) dos Cadernos que o compõem, entre eles o Caderno Opinião, o qual veicula o gênero "artigo de opinião", foco deste artigo. O objetivo da elaboração desse modelo teórico foi servir de suporte para a produção de material didático, na segunda etapa da pesquisa, cujo foco são as ações desenvolvidas no subprojeto PIBID de Português realizado na UENP. O modelo teórico privilegiou, principalmente, a análise do contexto de produção e do plano global do Caderno, como também uma pesquisa bibliográfica dos gêneros mapeados, entre eles, o artigo de opinião.

Na segunda etapa da pesquisa, o foco são as ações do PIBID, cujo objetivo maior é a construção de um jornal escolar (impresso), que, no ano de 2014, foi produzido colaborativamente entre alunos de duas escolas estaduais e de três turmas escolares da cidade de Cornélio Procópio, Paraná. O subprojeto PIBID contou com treze alunos-pibidianos e duas professoras da Educação Básica (professores supervisores) de colégios parceiros do programa (denominados Colégio A e B) em que as SDG foram desenvolvidas, com um coordenador responsável, professor de Licenciatura em Letras.

Para consolidar a transposição didática do jornal impresso para o contexto de ensino/aprendizagem, foram selecionados, tendo como modelo teórico (BARROS, 2012a), no Jornal Folha de Londrina - jornal de grande circulação na região em que esse projeto foi desenvolvido -, os seguintes gêneros para compor o jornal escolar: artigo de opinião; crônica humorística; carta do leitor, carta ao leitor, agendamento, anúncio publicitário comercial, anúncio classificado; reportagem temática, enquete, infográfico, foto/ legenda, sinopse de filme comentada, ficha técnica, horóscopo.

Para o processo de didatização desses gêneros, foram formados quatro grupos de trabalhos, cada qual atuando em um contexto de ensino específico. Os resultados trazidos neste artigo centram-se no grupo que trabalhou com a escola $\mathrm{B}$, turma $7^{\mathrm{O}} \mathrm{A}$, desenvolvendo uma SDG com o artigo de opinião. 
v. 8 (2)

$196-214$

mai/ago 2018

No início, quando pensamos no artigo de opinião, tivemos certo receio, pois é um gênero, de certa forma, complexo, que cobra bastante reflexão e conhecimento por parte dos alunos. Entretanto, dois pontos nos levaram a escolhê-lo: 1) a carência que os alunos possuem quando se trata de expor opinião, argumentar, defender um ponto de vista, ou seja, essa ausência de um letramento argumentativo; 2) o colégio em que iríamos desenvolver a SDG (colégio B) situa-se em uma região periférica da Cidade de Cornélio Procópio, com alunos com carência de letramento, principalmente argumentativo.

\section{A transposição didática pelo viés do Interacionismo Sociodiscursivo}

Segundo Machado e Cristóvão (2006), quando escolhemos um determinado "conjunto" de conhecimentos, nesse contexto, o gênero artigo de opinião, e nos propomos a ensiná-lo, esse objeto deve passar por uma série de modificações, a fim de que fique apto para o ensino. A esse processo dá-se o nome de transposição didática. Segundo Machado e Cristóvão (2006, p. 252), esse processo de transformação passa por três níveis básicos: 1) o "conhecimento científico" sofre uma primeira etapa de transformação, passando a ser um "conhecimento a ser ensinado"; 2) esse passa, posteriormente, a "conhecimento efetivamente ensinado"; 3) e depois a "conhecimento efetivamente aprendido".

Foi pensando nesse processo de transposição por que determinado conhecimento deve passar - nesse contexto, os gêneros de texto - para chegar a sala de aula, que o ISD elaborou ferramentas que permitem a "didatização" desses objetos: o modelo didático de gênero e a sequência didática (SD).

\section{A modelização do objeto de ensino: o primeiro processo da transposição didática}

De acordo com os estudiosos do grupo de Genebra, para que o processo de transposição didática de um gênero de texto seja efetivo, é necessário, primeiramente, a seleção e identificação dos "objetos ensináveis" desse gênero, o qual só é possível a partir de uma ferramenta que faça essa mediação. Essa ferramenta é denominada por esses autores de modelo didático, o qual, posteriormente, servirá como base para a construção de SDG. 
Para Dolz, Gagnon e Decândio (2010), o modelo didático é um instrumento que irá identificar e selecionar os "componentes ensináveis" de um determinado gênero, com o objetivo de levá-lo para o ensino. Assim, é uma ferramenta que evidencia a pesquisa dos saberes de referência em relação a um objeto de ensino determinado, a descrição das características do objeto, com base em um corpus de texto e a identificação das capacidades de linguagem dos estudantes.

Bronckart (2003), salienta que um modelo didático deve partir do estudo de um corpus de textos (do mesmo gênero), orientando-se pelo contexto de produção e pelas três camadas, a qual o autor denomina folhado textual: a) a infraestrutura geral do texto, b) os mecanismos de textualização e c) os mecanismos enunciativos. Segundo Gonçalves e Barros (2010, p. 45), "esses elementos de análise conseguem abranger os três níveis de capacidades de linguagem envolvidas na produção de um gênero".

De acordo com Dolz, Gagnon e Decândio (2010), a elaboração de um modelo didático deve ser orientada pelos seguintes princípios: a) princípio de legitimidade, referente aos saberes científicos ou elaborado por estudiosos do gênero; b) princípio de pertinência, refere-se à adequação dos saberes escolhidos ao contexto de ensino-aprendizagem escolar; c) princípio de solidarização, diz respeito à efetivação dos saberes desse gênero, com base nos objetivos de ensino esperados. São esses critérios, que, segundo os autores, comprovam a "validade didática" do modelo, o qual guiará a produção da SDG.

Barros (2012a, p. 77), complementando os estudos do Grupo de Genebra, introduz um novo conceito de modelização dos gêneros. Para a autora, o modelo do gênero "pode ser visto, a priori, apenas teoricamente, isto é, sua construção não necessitaria levar em conta as capacidades dos alunos nem as particularidades do contexto de ensino". Ou seja, essa modelização poderia se pautar em uma análise teórica do gênero, sem pensar de imediato no contexto de ensino. E um levantamento das características desse gênero, da forma como ele circula socialmente, seria um modelo do gênero de referência social. Esse modelo, posteriormente, pode ser didatizado, ou seja, adaptado a um contexto educacional específico.

Diferentemente dos pesquisadores de Genebra, distinguimos um processo de modelização preliminar, o qual denominamos modelo teórico do gênero. Ele vem sendo elaborado por vários pesquisadores que, ao descrever os conhecimentos subjacente aos mais variados gêneros, elaboram uma ferramenta 
v. 8 (2)

$196-214$

mai/ago 2018 fundamentalmente teórica (primeiro nível da transposição didática), cujo objetivo é servir de base para ações didáticas posteriores em um eventual processo de transposição didática. (BARROS, 2012a, p. 77; grifos da autora).

Dessa forma, o gênero, inicialmente, é visto apenas teoricamente, com uma análise geral de suas características, para que, posteriormente, esse modelo sirva como a base teórica na construção de modelos didáticos e sequências didáticas de gêneros (SDG). Vejamos o esquema a seguir:

Figura 1 - Ferramentas da transposição didática

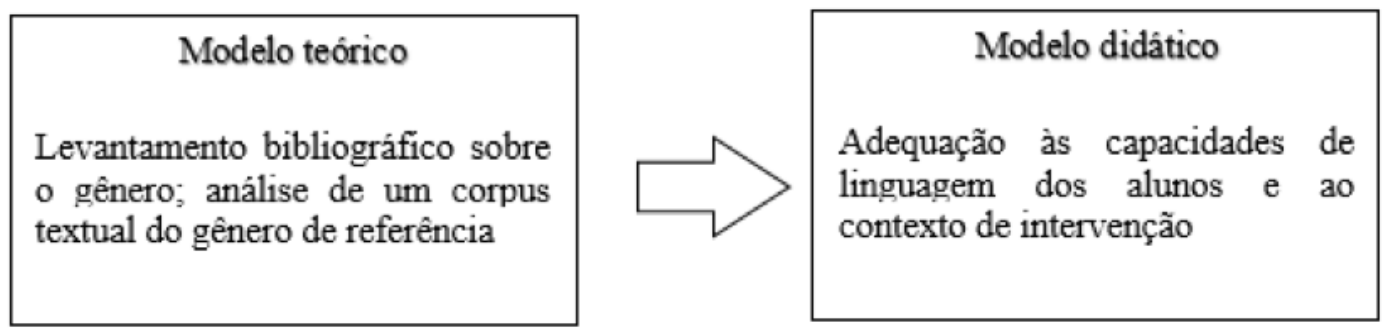

\section{Sequência didática do gênero}

Produção das atividades a partir das capacidades levantadas no modelo teórico/didático

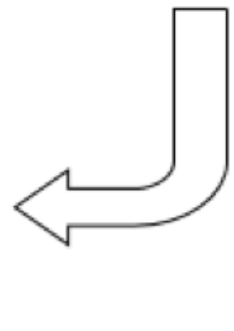

Fonte: elaborada pelas autoras.

Assim, primeiramente o foco recai sobre a análise teórica do gênero, levantando suas especificidades, sem pensá-las, de imediato, para o ensino. Posteriormente a construção do modelo didático, o qual modeliza essas dimensões apresentadas no modelo teórico, levando em conta um objetivo e contexto específico e por fim a didatização desse modelo a partir das atividades da SD.

\section{O processo de modelização do gênero "artigo de opinião"}

Para a produção do modelo teórico e/ou didático do gênero, Barros (2012a) elaborou um dispositivo didático que direciona o processo de modelização (ver BARROS, 2012b).

Segundo a autora: 
O dispositivo didático em questão parte da tripartição das capacidades de linguagem - de ação, discursivas e linguísticodiscursivas - , respeitando as categorias de análise textual do ISD, mas também incorporando outras características linguísticas/ discursivas consideradas pertinentes para a abordagem de um gênero. Ele [...] possibilita a elaboração de qualquer modelo teórico/didático, pois direciona o processo de modelização a partir de perguntas-chave, proporcionando uma visão mais pontual sobre o objeto de ensino analisado. (BARROS, 2012b, p. 11 - grifos da autora)

O dispositivo didático permite uma análise mais direcionada do gênero, pois possibilita que pensemos nele tanto teoricamente, realizando uma análise das suas características (enunciativas, contextuais, discursivas e linguísticas), como didaticamente, a fim de que essas características possam ser transformadas em objetos de ensino-aprendizagem em um determinado contexto de ensino.

Para a produção do modelo teórico do gênero "artigo de opinião" - o qual serviu de base, posteriormente, para a construção de uma sequência didática desse gênero - dividimos a pesquisa nas seguintes etapas: 1) pesquisa bibliográfica do gênero artigo de opinião; 2) seleção de um corpus de texto desse gênero; 2) análise desse corpus com base no dispositivo didático elaborado para a modelização do gênero (BARROS, 2012b). Essas etapas serão abordadas nos próximos tópicos.

\section{0 gênero artigo de opinião: a voz dos especialistas}

O gênero textual "artigo de opinião" é um gênero opinativo, característico da esfera jornalística, que permite ao seu autor explicitar e defender sua opinião sobre um determinado assunto polêmico de ordem social. Segundo Franceschini (2004, p. 146), o artigo de opinião é um gênero no qual seu autor "analisa um fato ou uma série de fatos em relação ao contexto político, social, econômico ou comportamental". Ele é um gênero que busca sempre convencer o seu leitor, tendo como eixo condutor uma tese sobre a polêmica. Por isso, o autor do artigo deve apresentar argumentos consistentes para que consiga defender seu ponto de vista e persuadir seu público leitor.

O "artigo de opinião" é um gênero publicado, normalmente, em jornais e revistas (tanto impressos como eletrônicos) e sites e blogs, e sempre é assinado. Apesar de ser um gênero característico da esfera jornalística, o artigo de opinião não precisa ser necessariamente produzido por um jornalista. Em muitos jornais e revistas, a produção do 
v. 8 (2)

$196-214$

mai/ago 2018

artigo de opinião é de responsabilidade de um articulista contratado ou convidado pelo jornal ou mesmo dos leitores desse jornal. Dessa forma, esse texto "possibilita o acesso a um grande número de indivíduos que podem ter sua participação tanto como leitores, quanto como escritores de seu próprio artigo" (UBER, 2008, p. 7).

Por ser um gênero opinativo, o artigo de opinião sempre aborda temáticas consideradas polêmicas, ou seja, que são passíveis de diferentes opiniões, defesas e argumentações, etc. A questão polêmica que direciona a discursividade é aquela "pergunta-chave" que inquieta o leitor/articulista e o motiva a escrever. Portanto, sem as questões polêmicas, não há motivação para se escrever um artigo de opinião, pois são elas que "geram discussões porque há diferentes pontos de vista circulando sobre os assuntos que as envolvem. Assim, o articulista, ao escrever, assume posição própria nesse debate, procurando justificá-la" (UBER, 2008, p. 20). São características, na formação do artigo, as seguintes peculiaridades discursivas:

Discussão de assuntos ou problemas sociais controversos, buscando chegar a um posicionamento diante deles pela sustentação de uma ideia, negociação de tomada de posições, aceitação ou refutação de argumentos apresentados (UBER, 2008, p. 4).

Dessa forma, o artigo de opinião permite ao autor se posicionar contra ou a favor de uma questão polêmica, de maneira implícita ou explicita em seu texto, e, assim, defender sua "tese", ou seja, aquilo que ele acredita, a partir de argumentos convincentes para que convença o seu leitor.

\section{O modelo teórico do artigo de opinião: análise de um corpus de texto}

Após a seleção do gênero "artigo de opinião", o qual seria o objeto da nossa SDG, iniciamos a produção do modelo teórico desse gênero. Para esse processo de produção do nosso modelo teórico, elencamos um corpus de quatro artigos de opinião:

1 - "Mistério ao final da copa das copas", publicado no Jornal Folha de Londrina no dia 25/05/2014, escrito por Eduardo Nascimento.

2 - "Heróis e vilões na Copa do Mundo", publicado no Jornal Folha de Londrina no dia 11/06/2014 e escrito por Gerson Leite de Moraes. 
3 - "O Brasil e a Copa", Publicado no Jornal Folha de São Paulo, no dia 11/05/2014, escrito por Abilio Diniz

4 - "Não maltratem a educação", publicado no Blog ZH, no dia 13/12/2013, escrito por Ricardo Russowsky

Os artigos citados acima foram objetos de análise durante a modalização do gênero, e, para esse processo, utilizamos como base o dispositivo didático elaborado por Barros (2012a). Na construção do modelo teórico, o foco recai sobre as capacidades de linguagens (DE PIETRO, SCHNEUWLY, 2003) envolvidas da construção do gênero. Essas capacidades, segundo Dolz e Schneuwly (2004, p.44) dizem respeito "as aptidões requeridas do aprendiz para a produção de um gênero numa situação de interação determinada" ou sejam, estão relacionadas as capacidades que são mobilizadas na produção e apropriação do gênero, as quais o sujeito deve dominar para efetivar seu domínio sobre esse objeto.

A capacidade de ação refere-se à representação da situação comunicativa, "aos parâmetros do ambiente físico, social e subjetivo, assim como ao referente textual" (BARROS, p. 113, 2015), ou seja, as questões contextuais que envolvem a produção de um gênero. A capacidade discursiva diz respeito aos recursos discursivos que são mobilizados pelo sujeito para a produção do texto/gênero. E por fim a capacidade linguístico-discursiva trata das operações linguísticodiscursivas que são empregadas na produção do texto/gênero.

Vejamos, então, a modelização do gênero artigo de opinião nos quadros a seguir: 
V. 8 (2)

$196-214$

mai/ago 2018
Quadro 1 - Modelo teórico do gênero artigo de opinião: capacidades de ação

\section{CAPACIDADES DE AÇÃO}

O artigo de opinião é um gênero escrito, característico da esfera jornalistica. Normalmente vem publicado em jornais, revistas e blogs no espaço/seção da opinião, e circula na sociedade em geral. Esse gênero é produzido por leitores dos respectivos jornais, revistas ou por articulistas contratados. Ele é um texto predominantemente opinativo, crítico, que surge sempre de uma questão polêmica. O artigo de opinião é bem flexível, permite que o autor coloque sua opinião sobre determinada polêmica, que critique, elogie, ou seja, posicione-se em relação a ela.

O artigo de opinião é um texto que busca sempre convencer o seu leitor. Por isso, o autor do artigo deve apresentar bons argumentos para que consiga defender seu ponto de vista e convencer seu leitor, que, na maioria das vezes, é o público-leitor que busca uma opinião contrária sobre determinada polêmica, quer ouvir uma outra voz.

Quando uma pessoa se propõe a escrever o artigo de opinião, assume um papel social de cidadão, pois irá se posicionar e mostrar seu conhecimento sobre a polêmica, aos receptores desse artigo, os leitores.

O artigo de opinião aborda assuntos polêmicos, que, na maioria das vezes, são atuais e de interesse social. A finalidade principal desse gênero é trazer a opinião dos leitores ou de articulistas especializados sobre temas de interesse público, a fim de mostrar aos leitores as diferentes opiniões que determinada polêmica pode receber. Dessa forma, o artigo de opinião permite que os leitores ou articulistas expressem seus pontos de vista e compartilhem-o com os leitores do veículo em questão. O enunciador do artigo de opinião pode defender seu ideal, expor seus argumentos e buscar convencer o seu leitor de que sua opinião é válida.

Fonte: elaborado pelas autoras. 
Quadro 2 - Modelo teórico do gênero artigo de opinião: capacidades discursivas

\section{CAPACIDADES DISCURSIVAS}

O artigo de opinião é um gênero do expor-interativo, produzido normalmente em $1^{a}$ pessoa do singular ou $1^{\text {a }}$ pessoa do plural, estruturado pela sequência argumentativa. Podem, evidentemente, aparecer outros tipos de sequências, como a descritiva, no momento em que o autor introduz e descreve a polêmica sobre a qual irá discorrer. Na composição do artigo, em alguns casos, o autor pode buscar outros gêneros para concretizar seu projeto argumentativo de dizer, como o ditado popular, a letra de música ou uma voz exterior (implícita ou explicitamente) sobre a polêmica que irá abordar. O autor do artigo nem sempre deixa explícito o tempo e o espaço em que escreve, porém é sempre um texto assinado e datado. Em alguns artigos, é normal ser publicado dados do articulista ao final do texto (sua profissão, cidade local).

O artigo de opinião é um texto em prosa. Possui normalmente uma página (podendo variar, dependendo da formatação do jornal/revista/ blog em que é publicado).

Esse gênero vem acompanhado de um título, que, em alguns casos, pode ser a própria questão polêmica do artigo, ou então uma frase que retrate a polêmica que será abordada de uma forma geral. Normalmente pelo título já consegue-se perceber um posicionamento do autor. Em geral, esse título é composto por uma frase nominal ou nominalizada. Não é comum o artigo de opinião vir acompanhado por imagens, entretanto, isso pode acontecer. O que normalmente acontece é o editor colocar uma fala do articulista bastante relevante em destaque com letras diferentes e de tamanho maior, o que no jornalismo é chamado de "olho".

- Esse gênero apresenta, discursivamente, argumentos e contraargumentos, os quais são característicos da sua formação, pois é a partir deles que o autor defende seu ponto de vista. Para argumentar, o autor do artigo traz argumentos apoiados em dados de pesquisa, de reportagens, levantamentos, evidências, exemplos, etc. Normalmente 0 autor traz a problemática que irá abordar logo nos primeiros parágrafos. Pode ou não já se posicionar. Na conclusão, normalmente, reforça seu posicionamento. Pode, às vezes, trazer um novo panorama para a polêmica, algo que suscite nova discussão. As vezes sua argumentação já é suficiente, de modo que ele não precisa nem se posicionar explicitamente. Ou seja, a argumentação do artigo pode ser textualizada de várias maneiras, tudo vai depender do projeto de dizer do articulista e da sua intenção discursiva.

Fonte: elaborado pelas autoras. 
V. 8 (2)

$196-214$ mai/ago 2018

Quadro 3 - Modelo teórico do gênero artigo de opinião: capacidades linguístico-discursivas

\section{CAPACIDADES LINGUÍSTICO-DISCURSIVAS}

No artigo de opinião, é presente o uso da retomada textual, que acontece tanto por meio de pronomes e sinônimos, termos genéricos ou específicos, e, em alguns casos, a própria repetição do termo (é comum no artigo haver essa alternância no momento da escrita - não é uma regularidade - isso serve para uma infinidade de gêneros).

Normalmente o articulista usa artigos definidos para se dirigir a algo sobre que está falando ou falou, pois já sabe a quem se refere, tem um bom domínio sobre o que está falando. Entretanto, em alguns casos, o artigo indefinido também é usado para causar um certo tom de distância, indiferença e crítica, característicos do artigo.

Esse gênero é estruturado predominantemente no tempo verbal presente, pois o autor situa sua fala no aqui e agora. É nessa temporalidade que ele discute, argumenta, critica, se posiciona. Entretanto, podem aparecer verbos que indicam ações do tempo passado e também ações do tempo futuro. Os verbos no artigo de opinião podem ser de duas modalidades: estado e ação. A incidência desses verbos varia de artigo para artigo, pois não há uma regra, entretanto, nota-se que verbos de ação são mais utilizados.

No artigo de opinião, se sobressai o uso de nomes - substantivos, pronomes, adjetivos - em detrimento de verbos.

Nesse gênero, a coesão ocorre, principalmente, por meio dos conectivos lógicos (mas, porém, portanto, afinal) e organizadores textuais, os quais são muito utilizađos. Outra forma utilizada para dar coesão a esse texto são as retomadas textuais.

O artigo de opinião é um gênero que respeita a norma culta da língua, entretanto, é possível que seu autor use, muitas vezes, uma linguagem mais informal. Isso é possível, pois, por seu teor argumentativo, o artigo prevê certo "diálogo" com o leitor, o que induz a uma interação discursiva com uma liberdade maior, porém dosada.

O vocabulário é sempre bem colocado, e, na maioria das vezes, está sempre no campo semântico da polêmica que o artigo aborda. No artigo de opinião, há a presença de substantivos, tanto concretos como abstratos, esses muitas vezes são usados para expressar o sentimento do articulista (triste, feliz, revoltado). Os adjetivos no artigo, muitas vezes, são usados para demonstrar tom de ironia, crítica e sarcasmo.

As metáforas podem ocorrer no artigo de opinião, quando o articulista quer utilizar a ironia ou sarcasmos para expressar seu ponto de vista. No artigo de opinião, são utilizados os sinais gráficos: ponto de exclamação (para entonar alguma ideia), ponto de interrogação (fazer perguntas retóricas, críticas, etc.) e dois pontos (introduzir uma conclusão lógica ou também uma ideia irônica).

A voz mais presente é a do autor, porém ele pode introduzir uma voz social exterior ou de um personagem, como de algum especialista na polêmica sobre a qual está discorrendo. As vozes sociais podem aparecer de forma explícita ou implícita.

Os temas que deflagram o artigo de opinião surgem sempre da esfera pública, dos debates coletivos, dos problemas sociais, podem, muitas vezes, surgir de vozes do senso comum, antes de passarem por um olhar analitico de instâncias políticas, partidárias, científicas.

Esse gênero, ao buscar o apoio de vozes externas, utiliza-se, normalmente, do discurso indireto. Quando apresenta o discurso direto, faz uso de recursos das aspas, diferentemente de gêneros narrativos, como o conto.

Fonte: elaborado pelas autoras. 
Nos quadros acima, são destacados os principais "conteúdos composicionais" e "relativamente estáveis" (BAKHTIN, 1992) do gênero artigo de opinião, delimitados através de uma análise do corpus estabelecido. A partir desse levantamento, são destacadas as capacidades que estão envolvidas na produção e apropriação do artigo de opinião. Para tanto, esse modelo, feito teoricamente, permite ao professor conhecer/entender seu objeto de ensino para, posteriormente, produzir seu modelo didático tendo como respaldo essa primeira análise.

\section{O modelo didático do gênero}

Após a modelização teórica do gênero, iniciamos a produção do modelo didático do artigo de opinião. Para a produção desse modelo, levamos em consideração o nosso contexto específico de ensino, abordando assim as capacidades de linguagem já apresentadas pelos alunos em relação ao artigo de opinião (investigadas por meio de avaliações diagnósticas) e aquelas que pretendíamos desenvolver durante a SDG.

O modelo didático teve como corpus principal o artigo de opinião "O Brasil e a Copa", publicado no Jornal Folha de São Paulo, no dia 11/05/2014, escrito por Abílio Diniz. As dimensões ensináveis levantadas a partir do modelo teórico e desse modelo didático, foram tomadas como objetos a serem didatizados nas oficinas da SDG. Vejamos uma síntese desse modelo didático 
v. 8 (2)

$196-214$

mai/ago 2018
Figura 2 - Modelo didático do artigo de opinião

Título: apresenta o tema central que será abordado no decorrer do artigo

O Brasil e a Copa

Uso da $1^{\mathrm{a}} \mathrm{p}$. singular $\mathbf{t}$

Início do texto: contextualização do tema; contraargumentacão (eu tenho o futebol como paixão (contraponto àqueles que possam pensar que ele não gosta de futebol); questão polêmica; premissa

Sempre declarei meu amor pelo Brasil. Trabalho para ajudar a melhorar este paí s, gerando empregos, dando aulas, apoiando iniciativas nas áreas de educação e esporte e investindo em empresas que possam contribuir para o seu crescimento. Como milhões de brasileiros, eu tenho o futebol como paixão. E N $\mathrm{N}$ O $\mathrm{AHO}$ QUE protestando contra a Copa diante dos olhos do mundo ganharemos alguma coisa. pelo contrário. Devemos aproveitar a atenção mundial para mostrar a grandiosidade e as oportunidades do Brasil. não os nossos problemas. Estes, resolvemos nós.

\section{Eixo temporal: presente}

Organizador textual que indica posição

A quase um mês da Copa do Mundo, vejo a bola rolando quadrada no país do futebol.

A festa que se previa deu lugar à tensão e ao ceticismo. Pesquisa Datafolha aponta que hoje mais brasileiros rejeitam a Copa do que a apoiam. É possível que saia mais gente às ruas do país para protestar contra o torneio do que para celebrá-lo.

enormes recursos humanos e materiais, uma das maiores democracias do mundo, uma economia de mercado de cerca de 200 milhões de consumidores, imprensa livre. Justiça independente. instituições sólidas. Quantos países têm essas credenciais?

Pergunta retórica
O interesse das grandes empresas e dos grandes empresários estrangeiros pelo Brasil é enorme, vejo quando viajo para o exterior para promover nossos produtos e o nosso mercado. E não são apenas os empresários. Existem interesse e simpatia generalizados por um país de povo tão criativo, alegre e empreendedor.

Durante a Copa do Mundo, um terço do planeta estará grudado nas telinhas para ver os jogos e, por tabela, o país que os sediará. Não tem cartão de crédito nem emissão de títulos da dívida pública que paguem essa massiva publicidade global. Precisamos aproveitá-la ao máximo. O Brasil ainda é pequeno em comércio internacional e atração de turistas. Argumento de causa e consequência: Brasil nas telas $\Rightarrow$ publicidade
Questão

polêmica

é relevante

protestar

contra a

Copa do

Mundo?

Premissa:

o autor é

contra os protestos; é

a favor da

celebração

do pais

\section{$\boldsymbol{1}$}


A intenção deste artigo não é desestimular ninguém a protestar. São muito justas as reivindicações por investimentos em educação, saúde, moradia, segurança e transportes. Com a nossa pesada carga de tributos, o Estado brasileiro deve, urgentemente, serviços mais eficientes e mais ética na gestão pública. Ter uma população mais engajada, exigindo serviços e gestão com a qualidade da nossa seleção e dos novos estádios, é saudável e legítimo.

$\longrightarrow$ Conectivo lógico: introduz uma refutação

Mas nós não podemos esquecer que a Copa do Mundo é uma das melhores oportunidades de projeção do país. Se a usarmos de forma eficaz na promoção da marca

Brasil, ganharemos muito. E quanto mais ganharmos com a promoção global do país. menos a Copa nos terá custado. Num mundo cada vez mais globalizado, a imagem ou marca de uma nação pode ser mais importante do que o que ele produz e vende.

Conectivo lógico: introduz um argumento O Brasil não é só um país em construção, mas uma marca em construção. Uma marca que reflete tudo o que somos: um gigante em paz com os vizinhos, um país com

Atrairemos muito mais recursos realizando uma Copa ordeira, que revele um país dinâmico, alegre e capaz de se organizar. Isso trará frutos para todos os brasileiros.

Retomada textual por pronome demonstrativo

Também acho que foram cometidos equivocos. Não precisávamos de tantas sedes e estádios tão caros em cidades sem torneios de futebol expressivo. As obras de mobilidade urbana poderiam ter sido entregues a tempo. Precisamos tirar todas as lições desses fatos lamentáveis.

Mas a bola, afinal, vai rolar. O Brasil, maior seleção da história, sediará uma Copa já especial pela presença de todas as grandes seleções e seus craques fabulosos. Que honra receber e, torçamos, derrotar Messi. Cristiano Ronaldo, Balotelli, Özil e Iniesta.

O Brasil é muito maior que as dificuldades que atravessamos. Está na hora de mostrar o nosso amor por este país - de começar a Copa cantando "sou brasileiro, com muito orgulho" e encerrá-la com "we are the champions". (Abílio Diniz) Ideia conclusiva: reforça a tese e apresenta uma conclusão que

Identifícação do autor mobiliza a voz do senso comum: trechos de músicas.

Fonte: elaborada pelas autoras.

O modelo acima, foi nossa base durante a produção da SDG. Nele estão expostas algumas das dimensões que foram privilegiadas no ensino do artigo de opinião, pois, como pontua Bronckart e Dolz (2004, p. 34 apud BARROS, 2012b, p. 22), "os modelos didáticos são modelos provisórios capazes de evoluir, e não prejulgam as formas efetivas do ensino, apenas abrem um leque de possibilidades". 
v. 8 (2)

$196-214$

mai/ago 2018

Vale ressaltar que esse processo de modelização didático se respaldou no modelo teórico, pois, a partir do momento que escolhemos esse texto do gênero artigo de opinião como nosso modelo a ser ensinado, tomamos como base o modelo teórico que nos trouxe uma análise inicial, a qual orientou todo os processos seguintes.

Assim, dentre as capacidades reveladas pelo modelo teórico, destacamos algumas delas que foram abordadas também no modelo didático e desenvolvidas durante a SDG:

Tabela 1 - Capacidades contempladas no modelo didático

\begin{tabular}{|c|c|c|c|}
\hline & Capacidade de Ação & Capacidade discursiva & \begin{tabular}{|c|} 
Capacidade \\
linguístico-discursiva
\end{tabular} \\
\hline $\begin{array}{l}\text { a) } \\
\text { b) } \\
\text { c) } \\
\text { d) }\end{array}$ & $\begin{array}{l}\text { O produtor emissor e } \\
\text { enunciador do gênero } \\
\text { artigo de opinião; } \\
\text { A esfera de produção e } \\
\text { circulação; } \\
\text { Os leitores (receptores) } \\
\text { do artigo de opinião; } \\
\text { Os veículos de circulação. }\end{array}$ & $\begin{array}{l}\text { a) Título; } \\
\text { b) Questão polêmica; } \\
\text { c) Ponto de vista (tese); } \\
\text { d) Argumentos; } \\
\text { e) Contra-argumentos } \\
\text { (exemplos, } \\
\text { pesquisas, dados). }\end{array}$ & $\begin{array}{l}\text { a) Retomada textual; } \\
\text { b) Organizadores } \\
\text { textuais; } \\
\text { c) Norma culta da } \\
\text { língua. }\end{array}$ \\
\hline
\end{tabular}
Fonte: elaborada pelas autoras.

Sendo assim, o modelo didático possibilita que visualizemos as potencialidades ensináveis de um gênero que podem ser transpostas para um determinado contexto de ensino. No caso do modelo apresentado, ele foi pensado para o contexto de intervenção do subprojeto PIBID de Português/Gêneros Textuais da UENP.

\section{Considerações finais}

Como o ensino de língua portuguesa tem-se voltado cada vez mais para o trabalho com os gêneros textuais, entre eles os que são contemplados na esfera jornalística, achamos pertinente que os professores possam ter cada vez mais contato com materiais e pesquisas em torno desses gêneros. Dessa forma, o objetivo desse artigo foi mostrar os resultados de um trabalho realizado a partir da modelização - teórica e didática - do gênero "artigo de opinião".

Esperamos que essa pesquisa contribua para o trabalho de muitos professores que pretendam tomar os gêneros jornalísticos como objeto de ensino, em especial, o artigo de opinião - foco deste artigo -, mostrando a esses educadores a necessidade e a importância de se conhecerem as características do gênero como objeto social, para depois transpô-lo para um universo didático particular. 


\section{Referências}

BAKHTIN, Mikhail Mikhaĭlovich. Estética da criação verbal. 2. ed. Livraria Martins Fontes, 1992.

BARROS, Eliana Merlin Deganutti. Gestos de ensinar e de aprender gêneros textuais: a sequência didătica como instrumento de mediação. 2012. 366 f. Tese (Doutorado em Estudos da Linguagem) - Universidade Estadual de Londrina, Londrina, $2012 \mathrm{a}$.

BARROS, Eliana Merlin Deganutti. Transposição didática externa: a modelização do gênero na pesquisa colaborativa. Raído, Dourados, MS, v. 6, n. 11, p. 11-35, jan./jun. 2012b.

BARROS, Eliana Merlin Deganutti de Barros. A capacidade de ação discursiva: representações do contexto de produção em situação de ensino-aprendizagem da escrita. Trabalho em Linguística Aplicada, Campinas, n. 54.1, p. 109-136, jan./jun. 2015.

BONINI, Adair. Os gêneros do jornal: o que aponta a literatura da área de comunicação no Brasil? Linguagem em (Dis)curso, Tubarão, v. 4, n. 1, p. 205231, jul./dez. 2003.

BRASIL, Ministério da Educação. Parâmetros Curriculares Nacionais: terceiro e quarto ciclos do Ensino Fundamental - Língua Portuguesa. Brasília: MEC/ SEB, 1998.

BRASIL. Ministério da educação. Orientações curriculares para o ensino médio: linguagens, códigos e suas tecnologias. Brasília: MEC/SEB, 2006.

BRONCKART, Jean-Paul. Atividade de linguagem, textos e discursos: por um interacionismo sócio-discursivo. 2. ed. Săo Paulo: EDUC, 2003.

CHEVALLARD, Yves. Les processus de transposition didactique et leur theorisation. 1984. Disponível em: http://yves.chevallard.free.fr/spip/spip/ article.php3?id_article=114. Acesso em: 15 jan. 2014 .

CHEVALLARD, Yves. On didactic transposition theory: some introductory notes. 1989. Disponível em: http://yves.chevallard.free.fr/spip/spip/IMG/pdf/ On_Didactic_Transposition_Theory.pdf. Acesso em: 15 jan. 2014.

De PIETRO, Jean-François; SCHNEUWLY, Bernard. Le modèle didactique du genre : un concept de l’ingénierie didactique. In : Théories-Didactique de la lecture-Écriture. Réseau Didactique, Université Charles-de-Gaulle: Lille, 2003.

DOLZ, Joaquim; NOVERRAZ, Michlèle; SCHNEUWLY, Bernard;. Sequências didáticas para o oral e a escrita: apresentação de um procedimento. In: SCHNEUWLY, Bernard; DOLZ, Joaquim (Org.). Gêneros orais e escritos na escolar. 3. ed. Campinas: Mercado das Letras, 2004. p. 95-128.

DOLZ, Joaquim; SCHNEUWLY, Bernard;. Gêneros e progressão em expressão oral e escrita: elementos para reflexões sobre uma experiência Suíça. In: SCHNEUWLY, Bernard; DOLZ, Joaquim (Org.). Gêneros orais e escritos na escolar. Campinas: Mercado das Letras, 2004. p. 95-128. 
V. 8 (2)

$196-214$ mai/ago 2018
DOLZ, Joaquim; GAGNON, Roxane; DECÂNDIO, Fabrício. Produção escrita e dificuldades de aprendizagem. Campinas: Mercado das Letras, 2010.

FRANCESCHINI, Felipe. Notícia e Reportagem: sutis diferenças. Comum, Rio de Janeiro, v.9, n.22, p. 144-155, jan./jun. 2004.

GONÇALVES, Adair Vieira. BARROS, Eliana Merlin Deganutti de. Planejamento sequenciado da aprendizagem: modelos e sequências didáticas. Linguagem \& ensino, Pelotas, v. 13, n. 1, p. 37-69, jan./jun. 2010.

MACHADO, Anna Rachel; CRISTÓVÃO, Vera Lúcia Lopes. A construção de modelos didáticos de gêneros: aportes e questionamentos para o ensino de gêneros. Linguagem em (Dis)curso, Tubarão, v. 6, n. 3, p. 547-573, set./dez. 2006.

PARANÁ. Secretaria de Estado da Educação Básica. Diretrizes Curriculares da Educação Básica - Língua Portuguesa. Paraná: SEED, 2008.

UBER, Teresinha de Jesus Bauer. Artigo de opinião: Estudos sobre um gênero discursivo. Artigo apresentado em conclusão ao Programa de Desenvolvimento Educacional da Secretaria de Estado da Educação do Paraná - PDE - , Maringá, 2008. 